\title{
la filosofía y sus ayudantes. relato de experiencia como ensayo
}

\author{
romina claudia magallanes ${ }^{1}$ \\ universidad nacional de rosario, argentina
}

resumen

El presente trabajo se propone realizar un recorrido por los conceptos de escrituras de "infancia", "devenir" y "ayudantes" tal como son pensados por W. Benjamin, G. Deleuze y G. Agamben y articularlos con experiencias realizadas en diversas comunidades filosóficas de un Colegio en Argentina, Joan Miró, en Funes, Santa Fe. La Filosofía infantil en el Colegio Joan Miró intenta y se anima a Reinar. A traer lo incumplido a su posibilidad, a pensar lo inolvidable olvidado de nuestras existencias, de la filosofía, sus filósofos, sus vicisitudes, cada día, cada saber, cada palabra, cada cosa. En un primer momento introductorio, se hace hincapié en la diferencia entre "experiencia" y "relato", luego el trabajo se adentra en los conceptos de "ayudantes" y "reino" a partir de los acontecimientos en los que tienen lugar los mismos en la obra de Benjamin y en las categorizaciones de Agamben. Previamente a dedicarse, finalmente, a la experiencia propia de los mencionados conceptos que es nuestro propósito exponer, el artículo realiza un repaso por los conceptos de infancia y devenir tal como los entienden Deleuze y Gagnebin. Elijo la forma del Ensayo, que cruza la experiencia, casi, intentado no separarse de ella objetivándola. Sino más bien, experimenta escribiendo aquello que tuvo lugar y que se expone, otra vez, en un tiempo indefinido, intermedio, que se despliega aún, en su lectura, y así, hace formar parte del acontecimiento.

palabras clave: infancia; devenir; ayudantes; experiencia; relato.

\section{a filosofía e seus ajudantes. relato de experiência como ensaio}

resumo

O presente trabalho se propõe a realizar um percurso pelos conceitos de escrituras de "infância", "devir" e "ajudantes" tal como são pensados por W. Benjamin, G. Deleuze e G. Agamben e articulá-los com experiências realizadas em diversas comunidades filosóficas de um Colégio na Argentina, Joan Miró, em Funes, Santa Fe. A filosofia infantil no Colégio Joan Miró tenta e se anima a Reinar. A trazer o incumprido a sua possibilidade, a pensar o inesquecível esquecido de nossas existências, da filosofia, seus filósofos, suas vicissitudes, cada dia, cada saber, cada palavra, cada coisa. Em um primeiro momento introdutório, se marca a diferença entre "experiência" e "relato", logo o trabalho se adentra nos conceitos de "ajudantes" e "reino" a partir dos acontecimentos nos que eles têm lugar na obra de Benjamin e nas categorizações de Agambem. Previamente a dedicar-se, finalmente, à experiência própria dos mencionados conceitos que é nosso propósito expor, o artigo realiza uma passagem pelos conceitos de infância e devir tal como os entendem Deleuze e Gagnebin. Escolho a forma do Ensaio, que cruza a experiência, quase, tentando não separar-se dela objetivando-a. Mas sim, experimenta escrevendo aquilo que teve lugar e que se expõe, outra vez, em um tempo indefinido, intermediário, que se desdobra ainda, em sua leitura, e assim, faz formar parte do acontecimento.

palavras-chave: infância; devir; ajudantes; experiência; relato.

\footnotetext{
${ }^{1}$ Email: romina_magallanes@yahoo.com.ar. 


\section{philosophy and its helpers. Report of experience as an essay}

abstract

The present work proposes a course through the concepts of "childhood", "becoming" and "helpers" concepts as they are thought by W. Benjamin, G. Deleuze and G. Agamben and articulate them with experiences taken in diverse Philosophical communities of a School in Argentina, Joan Miró, in Funes, Santa Fe. Children's philosophy in the College Joan Miró tries and is encouraged to Reign. In bringing the unfulfilled to its possibility, in thinking the unforgettable forgetfulness of our existences, of philosophy, its philosophers, its vicissitudes, every day, every knowledge, every word, every thing. $\mathrm{n}$ an introductory first moment, the difference between "experience" and "story" is marked, then the work goes into the concepts of "helpers" and "kingdom" from the events in which they take place in Benjamin's work and in the Agambem categorizations. Before finally devoting ourselves to the experience of the aforementioned concepts that it is our purpose to expose, the article makes a passage through the concepts of childhood and becoming as understood by Deleuze and Gagnebin. I choose the form of the Essay, which crosses the experience, almost, trying not to separate from it, by objectifying it. Rather, experience themselves writing the one that has taken place and exposes themselves, again, in an indefinite, intermediate time, which unfolds even in his reading, and thus, forms part of the event.

keywords: childhood; becoming; helpers; experience; report. 
la filosofía y sus ayudantes. relato de experiencia como ensayo

Sofía: ¿Qué pasaría si viviéramos en una estrella? ¿ ¿n una estrella fugaz?!

Lucio: Uf. Nos pasaríamos la vida pidiendo deseos.

Fugacidad y deseos. El esfuerzo del deseo y la fugacidad de la vida en una estrella. Una imagen para empezar. Una infancia de proyecciones de mundo para empezar.

\section{experiencia y relato}

Relatar una experiencia es una especie de discordancia. Relatar, a veces, en general, supone ordenar, dar cierta perspectiva a un acontecimiento que tuvo lugar, si lo tuvo, irrumpiendo sin esta posterior ordenación. Como dice Agamben, la experiencia ha estado ausente mucho tiempo:

la expropiación de la experiencia estaba implícita en el proyecto fundamental de la ciencia moderna [...] $(2007$, p. 13) En su búsqueda de la certeza, la ciencia moderna anula la separación y hace de la experiencia el lugar -el "método", es decir, el camino- del conocimiento. [...] Pues la gran revolución de la ciencia moderna no consistió tanto en una defensa de la experiencia contra la autoridad [...] sino más bien en referir conocimiento y experiencia a un sujeto único, que solo es la coincidencia de ambos órdenes en un punto arquimédico abstracto: el ego cogito cartesiano, la conciencia. (AGAMBEN, 2007, p. 18).

Agamben considera que en la idea de inconsciente freudiano se evidencia la crisis del concepto moderno de experiencia, ya que la misma no es subjetiva, no es experiencia de un yo, sino de una tercera persona, Es, o Ello. A partir de esta apertura, Agamben, dialogando con Benjamin y Heidegger, entre otros, expone una nueva noción de experiencia, que es una experiencia de lo nuevo, de lo desconocido; una experiencia que no es abordable para neutralizarla en un saber, como sucede en la concepción moderna (AGAMBEN, 2007, p. 55). Esta experiencia acontece, justamente, en el extrañamiento, en lo no vivido (AGAMBEN, 2007, p. 56).

Por esto, elijo la forma del Ensayo, que cruza la experiencia, casi, intentado no separarse de ella objetivándola. Sino más bien, experimenta escribiendo aquello 
que tuvo lugar y que se expone, otra vez, en un tiempo indefinido, intermedio, que se despliega aún, en su lectura, y así, hace formar parte del acontecimiento.

Este Ensayo de experiencia se conforma, así, entre descripciones de una historia construida a partir de todo lo novedoso que tenía lugar, de los esfuerzos y proyectos que buscaban propiciar experiencias filosóficas; y una nostalgia por esos momentos donde irrumpe lo no dicho ni vivido, donde acontecen las palabras nuevas.

\section{los ayudantes}

En un maravillo ensayo de G. Agamben, “Los ayudantes” compilado en el libro Profanaciones, el filósofo italiano nos presenta un mundo paralelo habitado por seres peculiares que, si bien nos acompañan, y lo hacen de una forma determinante para nuestra existencia, no parecen ayudarnos en algo productivo. Ellos aparecen en las novelas de Kafka, de Walser, en el cine y llenan las obras de literatura infantil "acaso porque el niño es un ser incompleto", según tradicionales concepciones de infancia. Hadas, genios caprichosos, caracoles que hablan, Pinocho mismo, el perfecto ayudante. Son seres que testimonian su pertenencia a otro mundo, a un "mundo complementario" que aluden "a una ciudadanía perdida o a otro lado inviolable" (AGAMBEN, 2000, p. 37-8).

Entre las cosas, sigue Agamben, también existen ayudantes:

Quién no conserva estos objetos inútiles, mitad recuerdo, mitad talismán, de los cuales se avergüenza un poco, pero a los cuales no quisiera por nada del mundo renunciar. Se trata, a veces, de un viejo juguete que sobrevivió a los estragos infantiles, de un estuche de escolar que custodia un olor perdido o de una camiseta escogida que seguimos guardando, sin ninguna razón, en el cajón de las camisas "de hombre". Algo por el estilo debía ser, para Kane, el trineo Rosebud (AGAMBEN, 2000, p. 40).

Donde van a parar esos objetos - ayudantes. Y qué son.

"El ayudante es la figura de lo que se pierde", de la "relación con lo perdido".

A través de ese ayudante puede darse una relación con lo perdido. Él se vincula con aquello que se olvida. A cada instante, hay una "masa infinita de lo que por sí se pierde irremediablemente" el recuerdo, la conciencia, el sujeto, el 
lenguaje, son excedidos por "el derroche ontológico que llevamos con nosotros" (AGAMBEN, 2000, p. 43), y olvidamos.

Pero este caos informe de lo olvidado, que nos acompaña como un golem silencioso, no es inerte ni es ineficaz. Por el contrario, actúa en nosotros con no menos fuerza que los recuerdos conscientes, si bien de una manera distinta. Constituye una fuerza y una invectiva de lo olvidado que no puede medirse en términos de conciencia ni ser acumulado como un patrimonio, pero cuya insistencia determina el rango de todo saber y de toda conciencia. Aquello que lo perdido exige no es ser recordado o complacido, sino permanecer en nosotros en tanto que olvidado, en tanto que perdido, y únicamente por esto, inolvidable. En todo esto el ayudante cumple un papel importante. Él es quien deletrea el texto de lo inolvidable y lo traduce a la lengua de los sordomudos. De allí su gesticular obstinado, de allí su impasible rostro de mimo. De allí, incluso, su irremediable ambigüedad. (AGAMBEN, 2000, p. 43-4).

Los ayudantes, a veces son palabras. Las palabras de la infancia salen al paso, dice Benjamin: "En ella se custodia lo insondable con lo cual los nombres de la infancia de pronto se presentan al adulto. Ese largo silencio los ha transfigurado por completo" (AGAMBEN, 2011, p. 17).

La palabra a la que Benjamin refiere es Brauhausberg. Se trata de un lugar donde pasaba los veranos con su familia. Aquella palabra, ahora, dice en "Caza de mariposas", se ha vaciado de significado, y realizado una experiencia de la semejanza- tal como la explica en "Sobre la facultad mimética", donde resalta que se trata de un acto puramente infantil (BENJAMIN, 2010, p. 149). Allí escribe:

Pero el nombre perdió su gravedad, y nada tiene que ver para mí ya con su cervecería: ahora es solamente esa montaña rodeada de azul que se alzaba en verano para alojarnos, a mí y a mis padres. Por eso anida el Potsdam de mi infancia dentro de un aire azul, del mismo modo que si sus mariposas se esparcieran sobre uno de esos brillantes esmaltes de Limoges en los que las almenas y las murallas de Jerusalén destacan contra un fondo azul oscuro (2011, p. 17).

Lo mismo ocurrió con la palabra "grabados en cobre" (kupferstich) y "sacar la cabeza" (kopfvertich). Benjamin escribe que un día escuchó pronunciar la palabra "grabados en cobre", y al día siguiente, tras esconderse debajo de una silla y luego, de repente, sacar la cabeza de allí, le atribuyó tal significado. Kupfercobre- se asemeja a Kopf -cabeza-, y Stich -grabado- a verstich, sustantivo inventado a partir de los verbos verstecken -esconder- y stechen -sacar- (39, nota del traductor). Esa semejanza fue decisiva:

Al desfigurarme a mí mismo y la palabra, conseguí al fin lo que necesitaba para hacer pie sobre la vida. Y aprendí a disfrazarme en las 
palabras, que propiamente eran nubes. El don de reconocer las semejanzas no es más que un débil resto de la más que vieja obligación de tener que volverse similar y comportarse de forma similar. Y dicha obligación a mí me la planteaban las palabras. No las que me volvían similar respecto a los modelos de conducta; sino las que me hacían similar a las casas, muebles y vestidos (BENJAMIN 2011, p. 40).

Asimismo, sucede con otra palabra, la que da título al ensayo al que nos venimos refiriendo, "Mummerehlen". En la traducción de J. Navarro Pérez, "comadreles". Como le explicaron pronto, Muhme Rehlen -comadre Rehlen- , aparecía en un verso de una vieja canción infantil, pero "como "comadre" nada me decía, la criatura se me volvió un espíritu: era el espíritu de las comadreles" (BENJAMIN, 2011, p. 39). Expone, luego:

El versito está desfigurado, pero el mundo desfigurado de la infancia ahí encuentra sitio. La comadre Rehles, que ahí justamente tenía su asiento, en realidad ya había desaparecido cuando oí hablar de ella por primera vez. Las comadreles fueron todavía más difíciles de localizar. Algunas veces las adivinaba entre el vapor de la tapioca, en el mono que percibía sumergido en el fondo de un plato. Me comía la sopa para aclarar su imagen. Puede que tuvieran su casa en un lago y el agua indolente les sentaba como una esclavina de tonos grisáceos. No sé qué se contaba sobre ellas, o qué me querían contar sobre ellas. Ellas eran lo mudo, lo blando y borroso, que se nubla en el núcleo de las cosas como lo hace la nieve en las bolitas de vidrio. Varias veces me vi envuelto en esto. Por ejemplo, en cuanto pintaba. Los colores que no iba mezclando me coloreaban a mí mismo. Antes de añadirlos al dibujo, me habían disfrazado por completo. Cuando se entremezclaban en la humedad de la paleta, yo los iba cogiendo poniendo tanto cuidado en el pincel como si fueran nubes deshilándose (BENJAMIN, 2011, p. 41-2).

Tanto en las palabras como en otros objetos, los ayudantes, a veces arruinados, feos, estropeados, con torceduras, joroba, con torpezas que son la forma que sume las cosas en el olvido constituyen para Agamben un Reino. "Y aquello que nosotros hemos olvidado por siempre es el Reino, nosotros que vivimos “como si no fuéramos Reino" (BENJAMIN, 2011, p. 42) “Reinar no significa cumplir con todo. Significa que lo incumplido es aquello que permanece".

Justamente con esta mirada comienza uno de los ensayos del mismo libro de Benjamin, "El hombrecito jorobado". Cuando era pequeño, a Benjamin le gustaba mirar por las alcantarillas y tragaluces que daban a los subterráneos, y también miraba a sus moradores, eran "chusma”, que lo miraban a su vez. De este tipo, dice Benjamin, era el jorobado. Su madre se lo reveló, lo llamaba "el 
Manazas", expresión evocada cada vez que "yo rompía algo o me caía al suelo" (BENJAMIN, 2011, p. 99). A todo aquel que este hombrecito miraba dejaba de poner atención tanto en sí mismo como en el jorobado, solo "estás aturdido ante algo que se ha roto en mil pedazos" (BENJAMIN, 2011, p. 99). Por otra parte, este "gobernador", como Benjamin lo llama, sólo hacía una cosa "cobrarme el tributo de ese medio olvido en cada una de las cosas que tocaba" (BENJAMIN, 2011, p. 100).

Pero, aún así -dice Benjamin- nunca lo vi. Sólo él me veía. Y con tanta más penetración cuanto menos me veía yo a mí mismo.

Creo comprender que el contenido de ese "toda la vida" que se dice que
pasa ante la mirada del que muere se encuentra formado por imágenes
como las que el hombrecillo jorobado va acumulando de nosotros. Pasan
rápidamente, como hojas de los librillos rígidamente encuadernados que
fueron como los antecedentes de nuestro actual cinematógrafo [...] El
hombrecillo también tiene mis imágenes. Él me miraba desde el
escondrijo y ante el estanque de la nutria, como me miraba en la mañana
de invierno y ante el teléfono en el pasillo de atrás, en la Montaña de la
cervecería con sus inagotables mariposas [...]. Ahora ha terminado su
trabajo. Pero su voz, que recuerda los murmullos propios de la lámpara
de gas, aún me susurra en el umbral del siglo: "Te lo ruego, hijo mío /
reza también por este jorobado hombrecillo (BENJAMIN, 2011, p. 100).

Finalmente, ya que éste es el último ensayo del libro, parece ser el jorobado quien escribe aquellas páginas de Infancia en Berlín, y que, así, Benjamin se desfigura, se suprime en esta figura, y es ella la que ha recaudado lo olvidado, lo desfigurado, la infancia.

Gabnebin se detiene en el libro Infancia en Berlín, donde pone de relieve que no se trata de una autobiografía, ni de idealizar la infancia ni de verla como un paraíso perdido que el adulto puede remembrar por escrito. Por el contrario a Benjamin le interesa en exponer cierta experiencia como infancia. En primer lugar esa experiencia es una reflexión desde el presente que descubre una infancia en signos perdidos, señales que el presente debe descifrar, sendas que se pueden retomar, no recorridas, abandonadas. En este sentido la experiencia de infancia lo es de aquello que podría haber sido diferente, "una relectura crítica del presente de la vida adulta" (BENJAMIN, 2011, p. 179).

Luego, hay otra dimensión de la infancia que tiene que ver con inhabilidades, desorientaciones, con cierta incapacidad preciosa, que muestra una 
esencial relación de desajustamiento del hombre con el mundo, de una inseguridad primera, una no soberanía. La infancia percibe desde un campo de percepción diferente al adulto, cosas que estos ya no ven. Figuras menores, como también objetos y palabras que no están solo a nuestra disposición para obedecer, sino, más bien, que se nos escapan, nos cuestionan, que son mucho más que instrumentos dóciles a nuestros propósitos.

Benjamin abre otra dimensión del prefijo "in". Esa zona sin lenguaje, sin Logos, sin Razón; esa "falta" es una apertura que muestra que la humanidad de lo humano no tiene que ver únicamente con su fuerza, su poder, sino de una forma más secreta y esencial con sus faltas y flaquezas, con ese vacío de Logos, que no debería encubrirse sino más bien acoger. La infancia como dice Lyotard, puede ser inhumana en el sentido de que tal incomplitud es una invención de lo posible.

La Filosofía infantil en el Colegio Joan Miró intenta y se anima a Reinar. A traer lo incumplido a su posibilidad, a pensar lo inolvidable olvidado de nuestras existencias, de la filosofía, sus filósofos, sus vicisitudes, cada día, cada saber, cada palabra, cada cosa.

\section{los ayudantes de los chicos}

Candela, una estudiante de Primer grado "Quiroga" eligió por objeto ayudante a un gran oso de peluche amarillo. Casi tan grande como ella lo trajo a la escuela -con el esfuerzo que conlleva cargar una inmensa mochila también- para exponer en la clase de filosofía su criatura infantil. Ese ayudante la acompaña desde su nacimiento. Fue el regalo que conserva obsequiado, precisamente, el día mismo que nació. Es amarillo. Está un poco viejo. Ha dejado por ahí algún ojo. Es su elegido porque es el recuerdo del olvido de su llegada a la vida. Ella estaba ahí, pero aún no estaba. Cande, ahora, cargaba en sus brazos con fervor, lo inolvidable, pero sin recuerdo, y todos lo veíamos y tocábamos.

Sofía trajo un conejo, blanco, más pequeño. Algo estropeado, descolorido. Le recuerda algo que olvidó: a sus padres regalándoselo "cuando era chica”. Y Renata, trajo un reno, más pequeño, marrón, que le recuerda a su abuelo que no conoció, que murió y dejó a ese ayudante para que custodie lo olvidado. La pone 
triste pero la ayuda a recordar algo no vivido que insiste como incumplido en su objeto preferido.

Alma trajo una mariposa, aún más pequeña, con alas de tul, desprendidas del armazón en algunos costados. Y es que justamente son las alas su objeto ayudante, las que recuerdan su deseo de ser hada, su incumplido sueño de volar.

Les dije, porque siempre tiendo a sugerir mis propias prácticas de infancia (a pesar de que agrego: "si quieren, por supuesto", pero no sé si suena convincente), que guarden a esos objetos ayudantes, porque tal vez nunca dejen de encontrar en ellos un mundo perdido que sin embargo, es el nuestro (y ¿por qué será importante ese mundo? les pregunto ¿lo será?)

pensar los saberes. filosofía de la lengua: "la almohada". lectura y escritura entre el horror y el entusiasmo

Además de la hora de Filosofía semanal, nuestro colegio lleva a cabo una práctica denominada Pensar los saberes. Con ello nos proponemos abordar filosóficamente cada área curricular. En las horas de Lengua, nos dedicamos a trabajar en Filosofía de la lengua. En una oportunidad, lo hicimos leyendo a Horacia Quiroga, escritor argentino, a quien homenajearon en la escuela dando su nombre a uno de los salones. El de primer grado.

Con los chicos de quinto grado leemos sus geniales y sugestivos Cuentos de la selva -propuestos por Soledad y Cecilia, las docentes titulares- mientras pensamos qué es leer, qué es escribir, qué es la lengua. Entre las definiciones que los chicos propusieron nos encontramos con esta: “La lengua y la palabra. Son un sistema de signos, de voz, de comunicación, de miedo y la lengua también es un lápiz".

Les comento a los chicos que hay un cuento que me gusta mucho que se llama "El almohadón de plumas". Que lo lean si tienen ganas. Lo hacen, claro. Su entusiasmo siempre me entusiasma, me sorprende como si tuviera una magia que no merezco, que me llega como la felicidad. Les gusta. Les dio miedo. Se lo cuentan a los que no lo conocen, hacen gestos de terror, algunos miraron cortometrajes que circulan en internet. Comparan versiones, géneros y efectos. 
Alguien dice que el consejo del médico fue lo que terminó matando a la protagonista ya que la reconvino a permanecer en reposo, es decir, con su cabeza en la almohada, siendo justamente en ese objeto donde habitaba el bicho que consumía su vida hasta extinguirla ¿Pero cómo podría imaginar el saber médico una hipótesis tan sobrenatural, irracional?

Para muchos de nosotros la almohada evoca un tiempo perdido cuando hallábamos en ella el secreto, para siempre olvidado, de una extraña protección que nos salvaba de ciertos miedos y nos aseguraba entrar con confianza al mundo de los sueños. Ahora, cada uno de nosotros miraba su almohada de otra forma. Sospechábamos que quizás, también era un objeto ayudante de otros recuerdos olvidados no tan gratos. Y muchos de los chicos comenzaron a escudriñarla, antes de acostarse, para comprobar que su confortable compañero infantil no les jugara una mala pasada. Nos reímos mucho. Sin abandonar la inquietud. Cuando la experiencia filosófica de las cosas, aún y principalmente de las más cotidianas se instala en nuestros días, todo lo que existe nos inquieta. Las cosas no son simples cosas habituales, obvios objetos mundanos que no merecen la pérdida de tiempo de ser pensados. Las cosas, cada una brota inagotable de preguntas. La infancia se anima a esa experiencia primordial, condición de posibilidad de todo pensar.

\section{la filosofía, los objetos y el azar}

A veces el ayudante es un dado. Tiene algo de juguete y de prodigio, de objeto mágico porque a pesar de la precisión inapelable de sus seis números bien marcados es cosa del azar. Es como el templo lúdico donde el azar nos hace creer que somos nosotros los que jugamos con él.

El juego en el que nos vemos todos fascinados, en esta oportunidad los chicos de tercer grado, consiste en lanzar el dado a alguien que se proponga como receptor voluntario y al mostrarnos el número que el azar nos prodigó, yo, a veces ellos mismos, pido o piden que realice, según dicho número, dos o cuatro o tres comparaciones por similitud, hipótesis, definiciones, ejemplos, contraejemplos, imaginaciones -entre otras operaciones que Lipman denominó "Herramientas Filosóficas"'- sobre cualquier problemática. 
Tiré el dado y pedí que comparen un huevo y el pizarrón (sugerencia de un alumno, Juanchi, que por "azar" dijo "lo primero que me vino a la mente"). Las palabras de los chicos siempre son sorpresas, son novedades. Todos los ceros a la izquierda para la pedagogía son regocijos filosóficos para quien re-oye, por primera vez, en esa paradoja, a sus más admirados pensadores. Uma levantó la mano y dijo: “Los dos existen". Para los pensadores anteriores a Sócrates, y algunos pensadores medievales, que acaso por Heidegger pudieron ser leídos en esa perspectiva, no había sido captado el hecho de "existir", de que "hay" ser, el acontecimiento previo -no cronológico pero sí ontológico- durante el cual antes de que ser sea ser algo, primero es. La mesa es mesa, pero antes de ser mesa es. Existe, y luego, lo hace en forma de mesa. Uma, sentada en ese banco que le queda tan grande, con esa voz algo extranjera -porque vivió en Barcelona un tiempo y se le nota una mezcla de catalán y castellano y porteño rosarino- experimentó ese acontecer de la existencia. Dificilísimo para cualquier mortal. El huevo y pizarrón -como Uma, su voz, el banco donde se sienta, sus compañeros, yo- tienen en común que son, existen.

Ambos existen, decía Uma. Las voces siempre traen otras voces, y la de Parménides y Heidegger son de las que me gusta siempre volver y volver a oír. Sin embargo, esa soy yo, con mi arsenal de ideas previas y sobrevaloradas. Pero tus palabras, Uma, son las primeras, el origen del lenguaje. Existen, son; luego son “algo" específico: un huevo, un pizarrón.

Bianca y Pablo compararon la tristeza y un ventilador de techo -los dos pensaron lo mismo, pero Bianca había levantado la mano antes. Ante el repetido escenario de frustración que cada chica y chico experimentan ante una idea propia a la que no pudieron dar su voz, ante las consabidas palabras enseñadas "compartimos ideas con otros. A veces las expresan unos, a veces, vos", Pablo se resigna a comprender. A veces comprendemos solo así): “los dos en un momento, paran", dijo Bianca. Luego del hermoso silencio ante una imagen, una idea, que nos avasalla en sus sencillez y voluptuoso origen, y, acaso, en la secreta experiencia íntima de lo triste y del viento; Catalina y otros dijeron, “también la 
tristeza y el ventilador de techo en un momento empiezan, se prenden". Joaquín dijo también (el número del dado quiso ser tres): "los dos se sienten".

Las herramientas filosóficas -en este caso, la comparación por similitudsolo son filosóficas -y hasta pueden, a veces, ser ayudantes- si acontecen en el pensar. Pero jamás lo propician por sí mismas.

Un día, al final de la jornada nos quedamos conversando con Manuel, el profesor de teatro, Jorgelina, la directora académica, y yo. Manuel que comienza a trabajar con nosotros nos dice que quiere trabajar la problemática de la escucha. Clave entre las denominadas "herramientas filosóficas", y en todo diálogo que se precie de tal. ¿Pero qué es escuchar? ¿Cómo podemos trabajar la escucha? ¿Escuchamos de la misma manera que en el siglo XIX? ¿Puede ser la escucha un imperativo? O, como dice Borges pertenecerá a los verbos que no resisten esa modalidad, como amar, soñar, leer. Escuchar. “Escuchá!”. “Escuchémonos!”.

Emanuel, un acompañante terapéutico que acompaña en sus clases a Franco nos propuso coordinar con él una clase a partir de una especie de escultura en papel gigante de una oreja. Allí se colgarían diversos sentidos que cada uno otorgábamos a la acción de la escucha representada en uno de los órganos que la hace posible. Entre otras muchas cosas y condiciones. La idea surgió por un objeto-ayudante. Franco había dibujado las orejas de un búho, que todo sexto grado había confeccionado en grupos. La oreja dibujada fue tomando y transformándose a medida que pasaban las clases y los búhos se terminaban. Y luego fue representante de un mundo mayor que ya había trascendido a todos. Olvidamos. La clase propuesta no fue realizada. Pero la oreja que Franco puso al búho de su grupo formó parte de los ayudantes que nos alertan, no nos dejan caer en las limitaciones de la vida en acto, de la vida que queda en la conciencia, las planificaciones, los objetivos. Nos asusta allí, sucia, doblada, sobre la cabeza de ese búho de Atenea -que tampoco nos deja olvidar lo incumplido de la filosofíaenfrentándonos con la insistencia de lo incumplido, de lo olvidado, de lo no hecho, pero que no por ello es una fuerza que actúa en nosotros, es una invectiva.

La escucha, el escuchar reinan, y encontraremos quizás, si no lo tenemos frente a nosotros ya, pero aún no somos capaces de ver, de escuchar, su modo. 
Tanto la escucha, como toda "herramienta" deja de ser filosófica cuando pretende imponerse como un mecanismo. En cambio, cuando se enmarañan, se complican con las palabras, el dado, la almohada, los juguetes queridos y muy atesorados, con cada texto pensado en la íntima y común inquietud filosófica ensayan, entre nosotros, filósofos infantes, una experiencia.

Una experiencia que se prolonga hasta ahora, con ustedes, y quizás, más.

\section{referencias}

AGAMBEN, G. Infancia e historia. Destrucción de la experiencia y origen de la historia. Buenos Aires: Adriana Hidalgo, 2007. . Profanaciones. Buenos Aires: Adriana Hidalgo, 2005.

BENJAMIN, W. Infancia en Berlín hacia 1900. Buenos Aires: Alfaguara, 1982. . Ensayos escogidos. Buenos Aires: El cuenco de plata, 2010. . Cuadros de un pensamiento. Buenos Aires: Imago Mundi, 2013.

GAGNEBIN, J. M. Infância e pensamento. In: Sete Aulas sobre Linguagem, Memória e História. São Paulo: Imago. 2012.

QUIROGA, H. El almohadón de plumas. Buenos Aires: Losada, 2007. . Cuentos de la selva. Buenos Aires: Colihue, 1987. 